\title{
Locoregional gastric cancer: a narrative review of multidisciplinary management
}

\author{
Ari Pelcovits ${ }^{1,2}$, Khaldoun Almhanna ${ }^{1,2}$ \\ ${ }^{1}$ Alpert Medical School of Brown University, Providence, RI, USA; ${ }^{2}$ Division of Hematology-Oncology, Rhode Island Hospital, Providence, RI, USA \\ Contributions: (I) Conception and design: K Almhanna; (II) Administrative support: K Almhanna; (III) Provision of study materials or patients: All \\ Authors; (IV) Collection and assembly of data: A Pelcovits; (V) Data analysis and interpretation: All Authors; (VI) Manuscript writing: All authors; (VII) \\ Final approval of manuscript: All authors. \\ Correspondence to: Ari Pelcovits, MD. Hematology Oncology Fellow, Warren Alpert Medical School of Brown University, Rhode Island Hospital, 593 \\ Eddy St., Providence, RI, 02903, USA. Email: ari_pelcovits@brown.edu.
}

\begin{abstract}
Gastric cancer is one of the most common cancers worldwide. While relatively uncommon in the United States, worldwide it is the $5^{\text {th }}$ most common cancer diagnosed. Almost half of patients present with locoregional disease. Even with advanced surgical techniques and adjuvant perioperative treatment the prognosis for patients in this cohort is still dismal. Perioperative chemotherapy and/or radiation have been used in the last several decades in an attempt to improve outcomes in locally advanced resectable gastric cancer. In this article, we will review the development of these multimodal treatment strategies over the past two to three decades. We will compare these treatment modalities and their impact on survival outcomes. We will review the evidence for perioperative chemotherapy and radiotherapy, used in isolation and in combination. We will evaluate the evidence for these various treatment strategies and discuss how this impacts the current guidelines and recommendations. While advanced locoregional gastric cancer continues to carry significant mortality, several recent studies have added to the armament of treatment options and have seen significant improvement in progression free and overall survival in this patient population. Ongoing studies into perioperative management continue to investigate alternative treatment options and best practice for locally advanced resectable gastric cancer.
\end{abstract}

Keywords: Gastric cancer; perioperative chemotherapy; epirubicin, cisplatin, and fluorouracil (ECF); docetaxel, oxaliplatin, leucovorin and fluorouracil (FLOT)

Submitted Apr 24, 2020. Accepted for publication Jul 10, 2020.

doi: 10.21037/atm-20-3509

View this article at: http://dx.doi.org/10.21037/atm-20-3509

\section{Introduction}

Gastric Cancer accounts for only $1.6 \%$ of all new cancer diagnoses a year in the United States (US), with an incidence of 7.4 cases per 100,000 people per year. Worldwide however it is the 5 th most common malignancy diagnosed, accounting for $5.7 \%$ of all new cancer diagnoses and the $3 \mathrm{rd}$ most common cause of cancer related death, accounting for $8.2 \%$ of all cancer deaths $(1,2)$. Nearly three quarters of all diagnoses and deaths occur in Asia, where, specifically in Eastern Asia, the incidence rate is 22.4 cases per 100,000 people per year (2).

In the US, the median age of diagnosis is 68 , with an incidence rate nearly double in men compared to women (10.0 to 5.3 per 100,000), and significantly higher in Black and Asian/Pacific Islander American men (14.1 and 14.3 per 100,000 respectively) (1). The incidence and mortality rates have declined in the US over the past several decades, from a peak in the 1970s of 12.2 to 8.5 per 100,000 today. The overall 5 -year survival rate however is still slightly over $30 \%(1)$.

Approximately $50 \%$ of patients with gastric cancer are diagnosed at early stage where the disease is localized to the stomach or surrounding lymph nodes. The mainstay of treatment for local or regional gastric cancer is surgical 
excision however the addition of chemotherapy and/or radiation has been shown to improve survival since the early 2000's (3). The timing of chemotherapy (neoadjuvant and or adjuvant), the choice of chemotherapeutic agents, and the use of radiation have been a subject of debate over the last two decades.

We present the following article in accordance with the Narrative Review reporting checklist (available at http:// dx.doi.org/10.21037/atm-20-3509).

\section{Basis for multimodality treatment}

With the lack of established screening guidelines in the United States, the majority of patients are diagnosed when symptomatic. Initial staging workup entails determining primary tumor invasion, presence of regional nodal disease, and or presence of metastatic disease. Staging includes an upper endoscopy and endoscopic ultrasound with biopsy, CT chest abdomen and pelvis with oral and intravenous contrast, and PET/CT. If a very early stage disease is suspected (i.e., T1a), endoscopic ultrasound with endoscopic resection to determine depth of invasion is necessary. Staging laparoscopy to evaluate for peritoneal disease is utilized for patients with advanced locoregional disease who are felt to be candidates for perioperative chemotherapy (4).

The most widely used staging system for gastric cancer is the TNM staging system. T stage is determined by the depth of tumor invasion, from Tis (in situ disease without invasion into the lamina propria) through T4b (tumor invading through the serosa into adjacent structures and organs). $\mathrm{N}$ stage is determined by the presence of and number of regional lymph nodes involved and $M$ stage by the presence of metastatic disease. Treatment strategies are delineated by three categories: early stage $0-1(\leq \mathrm{T} 1 \mathrm{~b})$, advanced locoregional stage I-III ( $\geq \mathrm{T} 2$ or $\mathrm{N}_{+}$, and $\mathrm{M} 0$ ), or metastatic stage IV (M1) (4).

All patients with metastatic disease should be evaluated for palliative systemic therapy $v s$. best supportive care, including MSI, Her-2, and PDL-1 testing. Patients with early disease (minimally invasive or in situ, T1a) can be managed with endoscopic or surgical resection alone. Those with advanced locoregional disease, with potentially resectable disease whom either the primary tumor has invaded into or beyond the muscularis propria (T2 lesions) and/or in which nodal involvement is noted, are best served with a multimodality approach (4).

Multimodality therapy has been evolving over the past two decades (Table 1). In 2001 the landmark results of the U.S. Southwest Oncology Group Intergroup study (SWOG 9008/INT-0116) showed that the addition of chemoradiotherapy following surgical resection improved survival for patients with locoregional disease (3). In the randomized phase III trial, 556 people with adenocarcinoma of the stomach or gastroesophageal junction, were randomly assigned after surgical resection to adjuvant chemoradiotherapy or to no further care (surgery alone). The adjuvant chemotherapy consisted of fluorouracil at a dose of $425 \mathrm{mg} / \mathrm{m}^{2} /$ day and leucovorin at a dose of $20 \mathrm{mg} / \mathrm{m}^{2} /$ day, which were given for 5 days and subsequently followed by chemoradiotherapy given 28 days later. Chemoradiotherapy consisted of fluorouracil at a slightly reduced dose of $400 \mathrm{mg} / \mathrm{m}^{2} /$ day and leucovorin, and radiation at a total dose of 4,500 cGy. Radiation was delivered 5 days in a row per week over 5 weeks and the chemotherapy was delivered on the initial four days and final three days of radiation. A month after completion of radiation two further cycles of fluorouracil (at the initial dose of $425 \mathrm{mg} / \mathrm{m}^{2} /$ day) plus leucovorin were given a month apart. The median overall survival increased from 27 to 36 months with the addition of chemoradiotherapy. A 10-year update showed continued survival benefit of adjuvant chemoradiotherapy with a HR for overall survival of 1.32 (95\% CI, 1.10-1.60; $\mathrm{P}=0.0046$ ), and a HR for relapse free survival of 1.51 (95\% CI, $1.25-1.83$; $\mathrm{P}<0.001)$ (11).

The MAGIC trial also sought to investigate the use of chemotherapy in addition to surgical resection but in the perioperative setting (5). Five hundred and three patients with potentially resectable adenocarcinoma of the stomach were randomly assigned to either perioperative chemotherapy and surgery (250 patients) or surgery alone (253 patients). Chemotherapy consisted of three preoperative and three postoperative cycles of intravenous epirubicin, cisplatin, and a continuous intravenous infusion of fluorouracil (ECF). Each 3-week cycle consisted of epirubicin $\left(50 \mathrm{mg} / \mathrm{m}^{2}\right)$ and cisplatin $\left(60 \mathrm{mg} / \mathrm{m}^{2}\right)$ on day 1 , and fluorouracil $\left(200 \mathrm{mg} / \mathrm{m}^{2}\right)$ daily for 21 days by continuous intravenous infusion. Patients treated with perioperative chemotherapy had an improved 5-year progression free and overall survival, with an increase from $23 \%$ to $36 \%$ for overall survival and a hazard ration for progression of 0.66 (95\% CI, 0.53-0.81; $\mathrm{P}<0.001)$ (5).

\section{Choice and timing of perioperative treatment}

Several limitations of these two trials have been noted. The toxicities rates of these regimens (perioperative ECF 
Table 1 Studies of multimodal therapy for the treatment of resectable gastric cancer 2001-2019

\begin{tabular}{|c|c|c|c|c|}
\hline Article & $\begin{array}{c}\text { Year } \\
\text { published }\end{array}$ & $\begin{array}{l}\text { Number of } \\
\text { patients }\end{array}$ & Treatment modality & Finding \\
\hline SWOG 9008/INT-0116 (3) & 2001 & 556 & $\begin{array}{l}\text { Adjuvant chemoradiotherapy (fluorouracil) vs. } \\
\text { surgery alone }\end{array}$ & $\begin{array}{l}\text { OS benefit of chemoradiotherapy } \\
\text { (HR 1.32) }\end{array}$ \\
\hline MAGIC (5) & 2006 & 506 & $\begin{array}{l}\text { Perioperative chemotherapy (ECF) vs. } \\
\text { surgery alone }\end{array}$ & $\begin{array}{l}\text { OS benefit of chemotherapy } \\
\text { (HR 0.75) }\end{array}$ \\
\hline CLASSIC (7) & 2014 & 974 & $\begin{array}{l}\text { Adjuvant chemotherapy (capecitabine }+ \\
\text { oxaliplatin) vs. surgery alone }\end{array}$ & $\begin{array}{l}\text { OS benefit of chemotherapy } \\
\text { (HR 0.56) }\end{array}$ \\
\hline UK MRCOE05 (8) & 2017 & 897 & Neoadjuvant chemotherapy ECX vs. CF & No survival benefit of ECX over CF \\
\hline Artist II & 2019 & 538 & $\begin{array}{l}\text { Adjuvant chemotherapy vs. chemoradiotherapy } \\
\text { in D2 node positive disease }\end{array}$ & $\begin{array}{l}\text { No difference in DFS } \\
\text { (HR } 0.910, P=0.667)\end{array}$ \\
\hline
\end{tabular}

OS, overall survival; DFS, disease free survival; HR, hazard ratio; ECF, epirubicin, cisplatin, and fluorouracil; CF, cisplatin and fluorouracil; ECX, epirubicin, cisplatin, and capecitabine; FLOT, docetaxel, oxaliplatin, leucovorin and fluorouracil.

Table 2 Description and recommendations of extents of surgical resection for gastric cancer

\begin{tabular}{llll}
\hline Surgical resection & Viscera removed & Nodes removed & Recommendations \\
\hline D1 & Gastrectomy, greater and lesser omenta & Stations 1 to 7 & Minimal \\
D2 & Gastrectomy, greater and lesser omenta & Stations 1 to 12a ( $\geq 15$ lymph nodes) & Ideal \\
D3 & Gastrectomy, greater and lesser omenta & Stations 1 to 16 & Not recommended \\
\hline
\end{tabular}

or post-operative chemoradiation) were significant. In the SWOG/Intergroup study, $54 \%$ of patients had grade 3-4 hematologic toxicity and $34 \%$ of patients had grade $3-4$ GI toxicity. Only $64 \%$ of the patients intending to receive treatment with chemoradiotherapy were able to complete it. In the MAGIC trial $58 \%$ of people were unable to complete all treatments in the perioperative-chemotherapy group. Specifically, of the patients able to complete the preoperative chemotherapy $34 \%$ of them did not follow through with postoperative chemotherapy, mostly due disease progression, patient desire, or complications after surgery.

The SWOG/Intergroup study also only randomized patients following surgical resection, with the majority of patients having T3 or T4 tumors or having node positive disease. Other issues related to staging, as patients did not have staging laparoscopy prior to randomization in the MAGIC trial and $90 \%$ of patient had only a D0 or D1 lymph node dissection in which fewer than 15 lymph nodes were removed (Table 2). Retrospective analysis of several other studies have found that the benefit in adjuvant treatment is only for those patients who underwent a D1 lymph node dissection however those who had a complete D2 dissection (removal of $>15$ lymph nodes) received no benefit from adjuvant therapy (12).

With these questions and limitations in mind several studies over the next decade sought to investigate the choice of and timing of perioperative treatment.

\section{Perioperative chemotherapy}

\section{Dose adjustments and dropping epirubicin}

An FNCLCC and FFCD multicenter phase III Trial 
published in 2011 showed similar results to the MAGIC trial with lower rates of toxicity using cisplatin and fluorouracil (CF) alone without epirubicin (ECF) (6). Two hundred and twenty-four patients from 28 French centers were randomly assigned to either the chemotherapy plus surgery or surgery alone. Patients in the chemotherapy group received cisplatin at a dose of $100 \mathrm{mg} / \mathrm{m}^{2}$ and then a continuous infusion of fluorouracil over 5 days at a dose of $800 \mathrm{mg} / \mathrm{m}^{2} /$ day. Cycles lasted 28 days and they received a total of 6 cycles, two or three preoperatively and three or four postoperatively, if there was no evidence of disease progression and if the initial preoperative treatment was tolerated well. The 5-year survival rate of patients receiving CF in this study was $34 \%$ (compared to $36 \%$ on the MAGIC trial).

The need for epirubicin was compared directly in the neoadjuvant setting, with ECX (replacing fluorouracil with capecitabine) $v s$. CF in the UK Medical Research Council OE05 trial (8). A total of 897 patients were randomly assigned to received either ECX for four cycles preoperatively, to match the total number of cycles given in the MAGIC trial, or only two cycles of CF. In the CF arm, Cisplatin $\left(80 \mathrm{mg} / \mathrm{m}^{2}\right)$ was given on day 1 and fluorouracil $\left(1 \mathrm{~g} / \mathrm{m}^{2} /\right.$ day) was administered on days $1-4$. In the ECX arm, Epirubicin $\left(50 \mathrm{mg} / \mathrm{m}^{2}\right)$ and cisplatin $\left(60 \mathrm{mg} / \mathrm{m}^{2}\right)$ were given on day 1 and capecitabine $\left(1,250 \mathrm{mg} / \mathrm{m}^{2} /\right.$ day $)$ was given daily for all four cycles. The 3 -year survival rate and median overall survival were similar, $39 \%$ and $42 \%$, and 23.1 and 26.4 months, for CF and ECX respectively. The ECX arm had lower rates of completion of chemotherapy (81\% vs. 96\%).

\section{Alternative triple therapy}

With mounting evidence that epirubicin increased toxicity without providing additional survival benefit standard of care shifted towards a doublet model of fluorouracil and cisplatin/oxaliplatin (FOLFOX). In search of an alternative triplet therapy that could improve outcomes, a randomized phase III study was undertaken using an alternative triplet therapy (10). A total of 716 patients with resectable biopsy proven either stage cT2 or higher or nodal positive stage $(\mathrm{cN}+)$, or both, esophagogastric tumors, without evidence of metastatic disease, were randomized. The control group was given three pre and three postoperative cycles of epirubicin and cisplatin in addition to continuous fluorouracil or oral capecitabine, each cycle lasting 3 weeks (ECF/ECX). The experimental group received four pre and four postoperative cycles lasting 2 weeks each, which consisted of fluorouracil as a continuous infusion along with leucovorin, in addition to oxaliplatin and docetaxel (FLOT). The overall median survival in the FLOT group was 50 months as compared 35 months with ECF/ECX group. This survival advantage was seen without an increase in serious treatment related adverse events, which was $27 \%$ in both the FLOT and ECF/ ECX groups, or an increase in the number of treatment related deaths which was less than $1 \%$ in both groups.

\section{Perioperative chemo $+R T$}

The CRITICs trial sought to investigate whether the benefits of adjuvant chemo/RT seen in the SWOG/ Intergroup trial and the benefits of perioperative chemotherapy seen in the MAGIC trial could be combined (9). A total of 788 patients with resectable gastric cancer (stage IB to IVA) were randomized to receive either perioperative chemotherapy or neoadjuvant chemotherapy and adjuvant chemoradiotherapy. Perioperative chemotherapy consisted of three cycles (pre and post) of epirubicin, cisplatin or oxaliplatin, and oral capecitabine, each cycle lasting 3 weeks. Neoadjuvant chemotherapy was the same as the perioperative regimen above with postoperative chemoradiotherapy consisting of a total of 45 Gy delivered in 25 fractions over 5 weeks, given in conjunction with capecitabine and cisplatin. The median overall survival was statistically no different between the two groups, 43 months (95\% CI, 31-57) in the chemotherapy group and 37 months (95\% CI, 30-48) in the chemoradiotherapy group, showing no significant benefit of the addition of radiotherapy.

\section{Summary}

Perioperative FLOT has now become the standard of care for locoregional gastric cancer $(\geq \mathrm{T} 2$ and/or node +$)$ in patients well enough to tolerate this regimen with plans for surgical resection (4). ECF is no longer considered an alternative treatment option. A study comparing a perioperative two drug regimen (e.g., FOLFOX) to a threedrug regimen (e.g., FLOT) is needed.

\section{Surgical resection and adjuvant therapy}

Some patients requiring multimodal treatment may still undergo curative upfront surgical resection either due to provider/practice preference, obstruction and bleeding, or 
due to upstaging on pathologic findings post operatively necessitating further systemic treatment. Several studies have evaluated the role of chemotherapy in this setting as well. The SWOG/Intergroup study again was the foundation for this treatment paradigm, in which adjuvant chemoradiotherapy was found to improve survival.

As mentioned previously the SWOG/Intergroup trial was notable in that $90 \%$ of patient had undergone only a D0 or D1 lymph node dissection and there is some evidence that adjuvant chemoradiotherapy is only beneficial in this patient population as opposed to those undergoing a more extensive D2 dissection (12).

\section{Adjuvant chemotherapy}

The CLASSIC Trial sought to investigate the role of adjuvant chemotherapy alone in patients who had undergone a D2 dissection (7). Patients who had undergone a D2 gastrectomy with curative intent for non-metastatic $\geq$ stage II gastric cancer were randomized to receive adjuvant chemotherapy or to surgery alone. The chemotherapy consisted of eight cycles of oral capecitabine (21-day duration) in addition to oxaliplatin. There was a significant improvement in the 3 -year disease-free survival from $59 \%$ in the surgery alone group to $74 \%$ in the adjuvant chemotherapy group. This was however with a significant increase in grade 3 or 4 adverse events, which were reported in only $6 \%$ of the surgery alone group but in $56 \%$ of patients in the adjuvant chemotherapy group, the most common of which in the adjuvant chemotherapy group were nausea, neutropenia, and decrease in appetite.

\section{Adjuvant chemoradiotherapy}

The ARTIST Trial sought to specifically evaluate the role of adjuvant chemotherapy or adjuvant chemoradiotherapy in patients who had undergone a D2 lymph node dissection as part of their gastric cancer resection (13). In the chemotherapy arm, patients received six cycles of the XP regimen (capecitabine and cisplatin). Patients assigned to the XP/XRT/XP arm received two cycles of XP, then XRT (45 Gy of radiation delivered over 5 weeks with continuous capecitabine $825 \mathrm{mg} / \mathrm{m}^{2}$ twice daily during radiotherapy), followed by two additional cycles of XP.

In the study group as a whole there was no statistically significant benefit of chemo/XRT over chemo alone, however in a subgroup analysis of patients with node positive disease there was a statistically significant prolongation in DFS in the XP/XRT/XP arm (estimated 3 -year DFS rate of $77.5 \%$ ) when compared with the XPalone arm (3-year DFS, 72.3\%; $\mathrm{P}=0.0365)$. This led to the ARTIST II trial which set to specifically evaluate the role of chemo/XRT in this patient population (lymph node positive D2 dissection disease). Interim analysis showed no benefit of chemo/XRT over chemo alone for patients with node positive disease following D2 dissection, (HR 0.910, $\mathrm{P}=0.667)(14)$.

\section{Conclusions}

Advanced locoregional gastric cancer (defined as $\geq \mathrm{T} 2$ and/ or node + disease) is a common malignancy worldwide that carries with its significant mortality despite initial goals of cure at treatment onset. Advancements over the past several decades have elucidated a clear benefit of perioperative treatment in addition to surgical resection. We prefer perioperative treatment with neoadjuvant chemotherapy when cytotoxic chemotherapy can be tolerated up front. Perioperative FLOT chemotherapy should be considered for all patients who are felt can tolerate significant cytotoxic chemotherapy. Doublet chemotherapy is an alternative perioperative regimen for those who are unable to tolerate FLOT.

D2 nodal dissection is recommended for best surgical staging and outcomes. For those patients not receiving neoadjuvant chemotherapy as part of a perioperative regimen, adjuvant chemotherapy with or without radiation is a reasonable alternative. Radiation should be added postoperatively for patients who did not receive a D2 dissection with its role in node positive D2 dissection yet to be established (Artist II trial).

Randomized control trials are still needed to compare perioperative FLOT with a two-drug perioperative regimen (e.g., FOLFOX) to directly compare the risks and benefits of the additional cytotoxic therapy.

\section{Acknowledgments}

Funding: None.

\section{Footnote}

Provenance and Peer Review: This article was commissioned by the Guest Editor (Dr. Khaldoun Almhanna) for the series "Gastroesophageal Cancer 2020" published in Annals of Translational Medicine. The article was sent for external peer 
review organized by the Guest Editor and the editorial office.

Reporting Checklist: The authors have completed the Narrative Review reporting checklist. Available at http:// dx.doi.org/10.21037/atm-20-3509

Conflicts of Interest: Both authors have completed the ICMJE uniform disclosure form (available at http://dx.doi. org/10.21037/atm-20-3509). The series "Gastroesophageal Cancer 2020" was commissioned by the editorial office without any funding or sponsorship. KA served as the unpaid Guest Editor of the series and serves as an unpaid editorial board member of Annals of Translational Medicine from Nov 2019 to Oct 2021. KA reports personal fees from Merck, outside the submitted work. The authors have no other conflicts of interest to declare.

Ethical Statement: The authors are accountable for all aspects of the work in ensuring that questions related to the accuracy or integrity of any part of the work are appropriately investigated and resolved.

Open Access Statement: This is an Open Access article distributed in accordance with the Creative Commons Attribution-NonCommercial-NoDerivs 4.0 International License (CC BY-NC-ND 4.0), which permits the noncommercial replication and distribution of the article with the strict proviso that no changes or edits are made and the original work is properly cited (including links to both the formal publication through the relevant DOI and the license). See: https://creativecommons.org/licenses/by-nc-nd/4.0/.

\section{References}

1. SEER. SEER Cancer Stat Facts: Stomach Cancer. National Cancer Institute. Bethesda, MD.

2. WHO. Stomach Fact Sheet. Globocan. 2018.

3. Macdonald JS, Smalley SR, Benedetti J, et al. Chemoradiotherapy after surgery compared with surgery alone for adenocarcinoma of the stomach or gastroesophageal junction. N Engl J Med 2001;345:725-30.

4. Network Comprehensive Cancer Network. Gastric Cancer (Version 4.2019). Available online: https://www.nccn.org/ professionals/physician_gls/pdf/gastric_blocks.pdf

5. Cunningham D, Allum WH, Stenning SP, et al. Perioperative Chemotherapy versus Surgery Alone for Resectable Gastroesophageal Cancer. N Engl J Med 2006;355:11-20.

6. Ychou M, Boige V, Pignon JP, et al. Perioperative
Chemotherapy Compared With Surgery Alone for Resectable Gastroesophageal Adenocarcinoma: An FNCLCC and FFCD Multicenter Phase III Trial. J Clin Oncol 2011;29:1715-21.

7. Noh SH, Park SR, Yang HK, et al. Adjuvant capecitabine plus oxaliplatin for gastric cancer after D2 gastrectomy (CLASSIC): 5-year follow-up of an open-label, randomised phase 3 trial. Lancet Oncol 2014;15:1389-96.

8. Alderson D, Cunningham D, Nankivell M, et al. Neoadjuvant cisplatin and fluorouracil versus epirubicin, cisplatin, and capecitabine followed by resection in patients with oesophageal adenocarcinoma (UK MRC OE05): an open-label, randomised phase 3 trial. Lancet Oncol 2017;18:1249-60.

9. Cats A, Jansen EPM, van Grieken NCT, et al. Chemotherapy versus chemoradiotherapy after surgery and preoperative chemotherapy for resectable gastric cancer (CRITICS): an international, open-label, randomised phase 3 trial. Lancet Oncol 2018;19:616-28.

10. Al-Batran SE, Homann N, Pauligk C, et al. Perioperative chemotherapy with fluorouracil plus leucovorin, oxaliplatin, and docetaxel versus fluorouracil or capecitabine plus cisplatin and epirubicin for locally advanced, resectable gastric or gastro-oesophageal junction adenocarcinoma (FLOT4): a randomised, phase $2 / 3$ trial. Lancet 2019;393:1948-57.

11. Smalley SR, Benedetti JK, Haller DG, et al. Updated analysis of SWOG-directed intergroup study 0116: a phase III trial of adjuvant radiochemotherapy versus observation after curative gastric cancer resection. J Clin Oncol 2012;30:2327-33.

12. Dikken JL, Jansen EP, Cats A, et al. Impact of the extent of surgery and postoperative chemoradiotherapy on recurrence patterns in gastric cancer. J Clin Oncol 2010;28:2430-6.

13. Lee J, Lim DH, Kim S, et al. Phase III trial comparing capecitabine plus cisplatin versus capecitabine plus cisplatin with concurrent capecitabine radiotherapy in completely resected gastric cancer with D2 lymph node dissection: the ARTIST trial. J Clin Oncol 2012;30:268-73.

14. Park SH, Zang DY, Han B, et al. ARTIST 2: Interim results of a phase III trial involving adjuvant chemotherapy and/or chemoradiotherapy after D2-gastrectomy in stage II/III gastric cancer (GC). J Clin Oncol 2019;37:4001.

Cite this article as: Pelcovits A, Almhanna K. Locoregional gastric cancer: a narrative review of multidisciplinary management. Ann Transl Med 2020;8(17):1108. doi: 10.21037/ atm-20-3509 